\title{
Fabrication and Characterization of Glass Fiber with SiC Reinforced Polymer Composites
}

\author{
Rajashekar Reddy Palle, Jens Schuster, Yousuf Pasha Shaik, Monis Kazmi \\ Department of Applied Logistics and Polymer Sciences, University of Applied Sciences Kaiserslautern, Institute for Plastics \\ Engineering West Pfalz (IKW), Pirmasens, Germany \\ Email: rajashekarreddy703@gmail.com
}

How to cite this paper: Palle, R.R., Schuster, J., Shaik, Y.P. and Kazmi, M. (2022) Fabrication and Characterization of Glass Fiber with SiC Reinforced Polymer Composites. Open Journal of Composite Materials, 12, 16-29.

https://doi.org/10.4236/ojcm.2022.121002

Received: November 18, 2021

Accepted: January 3, 2022

Published: January 6, 2022

Copyright $\odot 2022$ by author(s) and Scientific Research Publishing Inc. This work is licensed under the Creative Commons Attribution International License (CC BY 4.0).

http://creativecommons.org/licenses/by/4.0/

\begin{abstract}
Glass Fiber Reinforced Polymeric (GFRP) Composites are most commonly used as bumpers for vehicles, electrical equipment panels, and medical devices enclosures. These materials are also widely used for structural applications in aerospace, automotive, and in providing alternatives to traditional metallic materials. The paper fabricated epoxy and polyester resin composites by using silicon carbide in various proportions along with GFRP. The hand lay-up technique was used to fabricate the laminates. To determine the properties of fabricated composites, the tensile, impact, and flexural tests were conducted. This method of fabrication was very simple and cost-effective. Their mechanical properties like yield strength, yield strain, Young's modulus, flexural modulus, and impact energy were investigated. The mechanical properties of the GFRP composites were also compared with the fiber volume fraction. The fiber volume fraction plays a major role in the mechanical properties of GFRP composites. Young's modulus and tensile strength of fabricated composites were modelled and compared with measured values. The results show that composites with epoxy resin demonstrate higher strength and modulus compared to composites with polyester resin.
\end{abstract}

\section{Keywords}

Polymer Matrix Composite, Epoxy and Polyester Resins, Silicon Carbide, Glass Fibers, Hand Lay-Up Technique, Modelling

\section{Introduction}

Plastic matrices reinforced with glass fibers are known as GFRPs. These materials consist of a plastic matrix reinforced with glass fibers. E-glass fibers are widely used in a wide range of industries due to their excellent properties, which make 
them lightweight, strong, and robust. As a base metal in polymer matrix composites, metal powders and metal alloys are gaining more attention. Because of their superior properties, they are being seriously considered for structural applications, including those in aerospace, transportation, defense, automotive (pistons, cylinder liners, bearings), and sports industries [1]. In this paper, the mechanical and machinability properties of silicon carbide particle (SiC-p) reinforced aluminum metal matrix composites were studied. Increasing the reinforcement element addition produced better mechanical properties, such as impact toughness and hardness. However, tensile strength showed a different trend, increasing up to $10 \%$ of SiC-p reinforcement and then decreasing when $15 \%$ of SiC-p reinforcement was added [2]. The objective of this study is to assess the chemical composition and thermal stability of ramie fibers after they have been washed with distilled water. Various fiber lengths $(25,35,45$, and $55 \mathrm{~mm})$ and fiber composition were examined when it comes to glass fiber and washed ramie fiber composites. In this experiment, the fiber loading was maintained constant. From the results obtained, washed ramie fiber may be considered as an alternative material for producing these composites. For composites with $45 \mathrm{~mm}$ fiber length, the higher flexural strength was observed, although this difference was not significant for lower glass fiber volume fractions (0:100) and (25:75). In addition, increasing the volume fraction of glass fiber to a maximum of $75 \%$ resulted in higher flexural and impact properties [3]. In this paper, the author has fabricated hybrid polymer composites with random oriented e-glass fiber in the unsaturated polyester resin matrix. Titanium oxide $\left(\mathrm{TiO}_{2}\right)$ was used as reinforcement material and kept 10 wt $\%$ constants. The fiber content was varied as $20 \mathrm{wt} \%, 25 \mathrm{wt} \%, 30 \mathrm{wt} \%, 35 \mathrm{wt} \%$, and $40 \mathrm{wt} \%$. The unsaturated polyester resin was used as a bonding agent. The composites were prepared with two different fiber lengths of $3 \mathrm{~cm}$ and $5 \mathrm{~cm}$ by hand lay-up method. Experiments were conducted to determine tensile strength, impact strength and hardness. The results showed that the combined reinforcement effect yields better mechanical properties with increased fiber length and particulate material [4]. Throughout this study, random oriented reinforced polymer composites made of E-glass fiber were developed by hand lay-up with differing fiber percentages $(15 \%, 30 \%, 45 \%$, and $60 \%)$. The influence of glass fiber percentage on mechanical properties such as tensile strength, bending strength, and impact strength was studied. Increasing the glass fiber content of the composite resulted in remarkable improvements in its mechanical properties [5]. This paper involves the fabrication of epoxy and polyester resin composites using aluminum oxide, silicon carbide along GFRP. A mixing unit has been fabricated for making reinforcement mixtures. Mechanical tests like tensile, impact, hardness, shear, bi-axial were conducted to know the properties of fabricated composites. The result shows that composites with epoxy resin show higher strength as compared to composites with polyester resin [6]. This paper aims to increase mechanical properties like the tensile, flexural, and impact strength to the extent of $16.8 \%, 7.8 \%$, and $13 \%$, respectively by the increased incorporation of nanoparticles for that the author has prepared a hybrid epoxy nanocomposite reinforced 
with woven roving glass fiber and cerium (IV)-zirconium (IV) oxide nanoparticles. These properties were studied at nanoparticle contents of $0.5 \mathrm{wt} \%, 1 \mathrm{wt} \%$, and $1.5 \mathrm{wt} \%$. Structural and morphological characterization was explored using $\mathrm{X}$-ray diffraction and field emission scanning electron microscope [7]. Two commercial types of reinforced glass fibers were investigated in this study: chopped and 0/90 fiberglass compounds with unsaturated polyester resin. A hand lay-up method was used in the preparation of the composites. A three-point bending test was used to evaluate the flexure properties. In the results, it was shown that pure unsaturated polyester UPE fractures at the maximum point. For fiber/polyester composites, different behavior was shown depending on the type of fiber [8]. This study examined the effects of glass content, composite thickness, reinforcement geometry, and type of fabrication on the damage developed during flexure tests for continuous random glass-polyester composites fabricated using Resin Transfer Molding (RTM) and Hand Lay-Up (HLU). The flexural strength and modulus of composites containing $20 \%$ and $30 \%$ continuous random fibers showed mean values of $84 \mathrm{MPa}$ and $7 \mathrm{GPa}$ and $110 \mathrm{MPa}$ and $10 \mathrm{GPa}$, respectively, for the Hand lay-up composites [9]. A Metal Matrix Composite (MMC) material is one of the most widely used composites because of its excellent properties, including high strength, hardness, stiffness, wear, and corrosion resistance. Aluminum-based MMCs reinforced with silicon carbide particles (SiC-p) are among the most common and economical ones [10]. The aim of this study was to investigate the mechanical properties of glass fiber/epoxy composite materials with variations in fiber volume fractions. Compression molding and hand lay-up methods were used in the manufacturing of composites. In the total composition, fiber volume fractions were maintained at about $40 \%, 50 \%$, and $60 \%$, respectively. A volume fraction of $50 \%$ produced better mechanical properties. Composites start delaminating when fiber content was increased further [11].

\section{Materials \& Methods}

\subsection{Materials}

\subsubsection{Glass Fiber}

E-glass fibers with small diameters are produced by extruding thin strands of silica glass. The reason why e-glass fibers were used in this study is that they are extremely strong, lightweight, and robust, making them ideal for composites when compared to metals. Moreover, the bulk strength and weight properties of this material are very favorable, and it is easily molded. A fiber-reinforced polymer composite is strong and lightweight since fibers are used as reinforcement agents.

\subsubsection{Epoxy Resin}

It is easy to incorporate epoxy resins (density: $1.44 \mathrm{~g} / \mathrm{cm}^{3}$ ) into composite laminates because of their high density and high adhesion between fibers when compared to other resins like vinyl ester resin (density: $1.4 \mathrm{~g} / \mathrm{cm}^{3}$ ), polyethylene resin (density: $0.9 \mathrm{~g} / \mathrm{cm}^{3}$ ). and polypropylene (density: $0.92 \mathrm{~g} / \mathrm{cm}^{3}$ ). LY 556 epoxy resin 
and hardener (HY 951) were used at room temperature to increase composite strength and interfacial adhesion.

\subsubsection{Polyester Resin}

In this study, Polyester (PE) was used as the matrix. It is a viscous liquid, transparent, thermosetting polymer type. The liquid converts to solid by adding hardener additives Methyl-Ethyl-Ketone-Peroxide (MEKP), which is a transparent liquid with $2 \%$ for each 100 gm of $\mathrm{PE}$ at room temperature.

\subsubsection{Silicon Carbide}

In an Acheson graphite electric resistance furnace, silicon carbide ( $\mathrm{SiC}$ ) is produced by combining silica sand and carbon at high temperatures. Under an inert atmosphere at low temperatures, it can also be prepared by the thermal decomposition of a polymer. In addition, it has a low density, high strength, high hardness, high thermal conductivity, and excellent thermal shock resistance. In composites, silicon carbide is one of the best filler materials. Table 1 lists the mechanical properties of $\mathrm{SiC}$.

\subsection{Preparation of Composite Specimens by Hand Lay-Up Technique}

In the present study, a hand lay-up technique was used to fabricate two laminates using epoxy and polyester resins. The materials used to fabricate the laminates were shown in Figure 1. Initially, the releasing agent was applied over the mold to facilitate the removal of the laminates. The $300 \mathrm{~mm}$ long and $300 \mathrm{~mm}$ wide E-glass fibers were laid in a normal direction after a thin layer of resin mixed with $\mathrm{SiC}$ was applied to the mold. A weight of $5 \mathrm{~kg}$ was placed over the fiber to remove any air bubbles, and the weight was left undisturbed for about 3 hours. On the surface of the first layer, the resin mixed with $\mathrm{SiC}$ was applied and rolled with rollers to achieve a homogeneous structure. After the third layer was laid on top, the resin was again spread over and rolled. This process was repeated until eight layers were formed. To remove the air bubbles, a weight of $10 \mathrm{~kg}$ was applied to the entire setup. It was then left for 24 hours to cure. The same procedure

Table 1. Mechanical properties of SiC.

\begin{tabular}{cc}
\hline PROPERTIES & SILICON CARBIDE \\
Density $\left(\mathrm{g} / \mathrm{cm}^{3}\right)$ & 3.3 \\
Tensile Strength $(\mathrm{MPa})$ & 588 \\
Coefficient of Thermal Expansion $\left(10^{-6} /{ }^{\circ} \mathrm{C}\right)$ & 4.6 \\
Young's modulus $(\mathrm{GPa})$ & 137 \\
Shear Modulus $(\mathrm{GPa})$ & 51 \\
\hline
\end{tabular}


was repeated for all compositions containing (5\%, 10\%, 15\%, and 20\%) $\mathrm{SiC}$.

\subsection{Mechanical Testing}

\subsubsection{Tensile Test}

The fabricated hybrid composite material was cut using a saw cutter and the edges were finished with emery paper for mechanical testing. Tensile specimens were prepared with dimensions of $2 \mathrm{~cm}$ wide and $15 \mathrm{~cm}$ long. During tensile tests, specimens were mounted on machines, and tension was applied. Tension was applied to the test specimen until it fractured in the testing machine. As the gauge length increases, the tensile force increases as well. The gauge section was measured with the applied force as tension was applied. A total of eight specimens with varying $\mathrm{SiC}$ compositions were prepared for the test. Figure 2 and Figure 3 show the specimens fabricated with epoxy and polyester resins after the test. The experiments were repeated several times, followed by an analysis of the average value.

\subsubsection{Flexural Test}

Flexural specimens were prepared according to ASTM D790. For composite

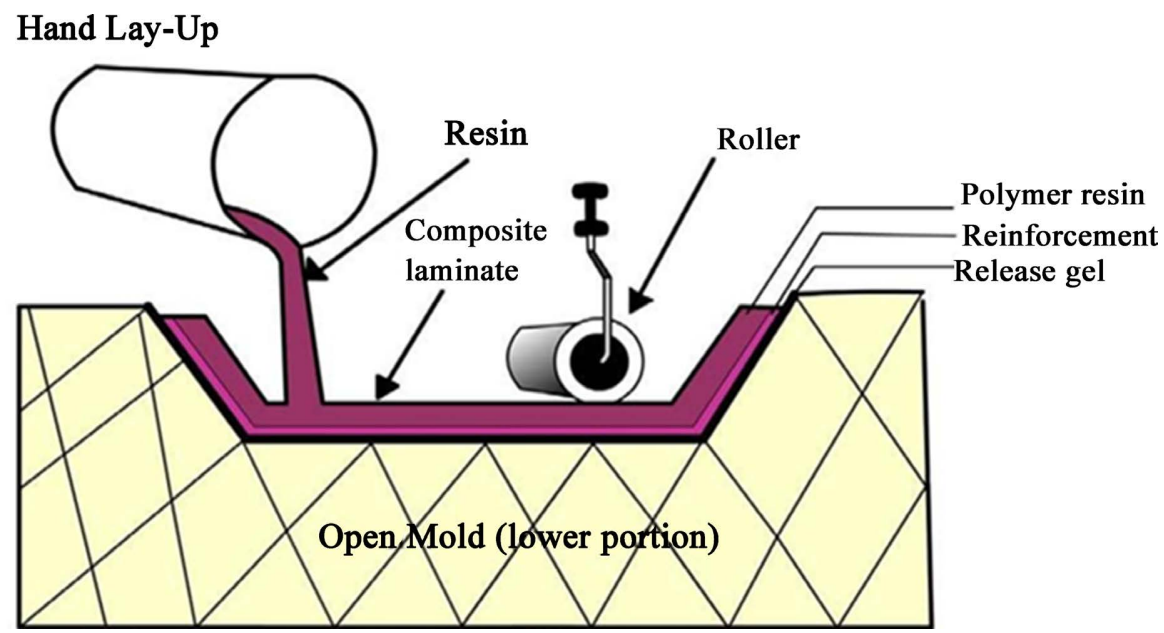

Figure 1. Hand lay-up process.

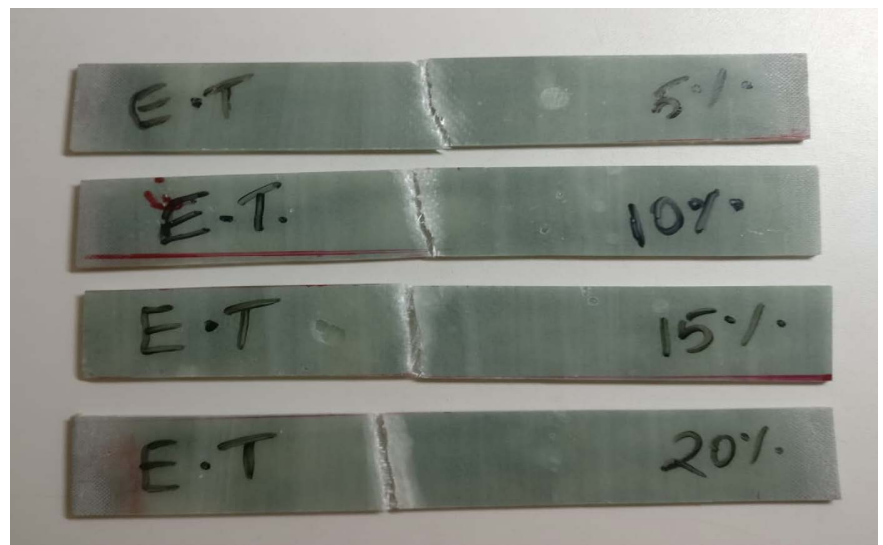

Figure 2. Tensile tested epoxy samples (SiC). 
materials, the 3-point flexure test is the most common. The test specimen was placed in the universal testing machine and subjected to force until it fractured. The deflection of the specimen was measured using the crosshead position. Deformation and flexural strength were also assessed. Figure 4 and Figure 5 show the specimens after the flexural test. Testing was performed at a temperature of

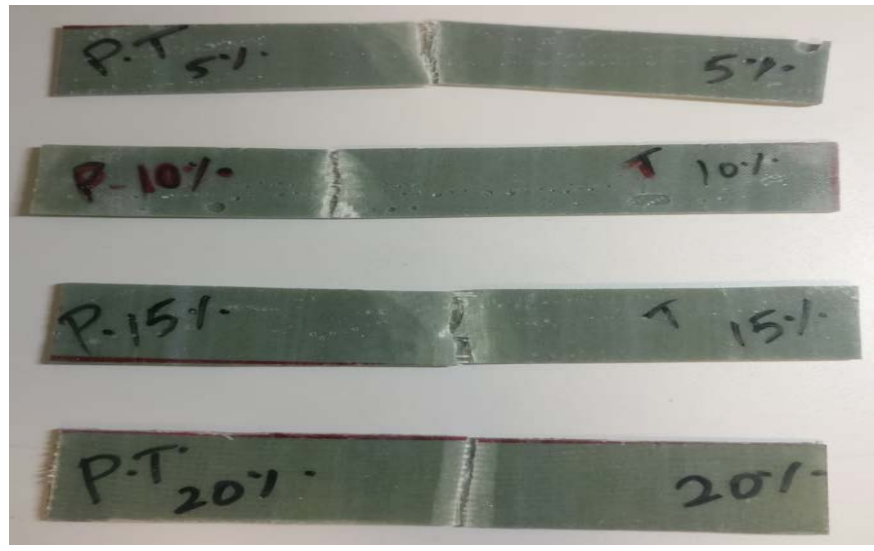

Figure 3. Tensile tested polyester samples ( $\mathrm{SiC})$.

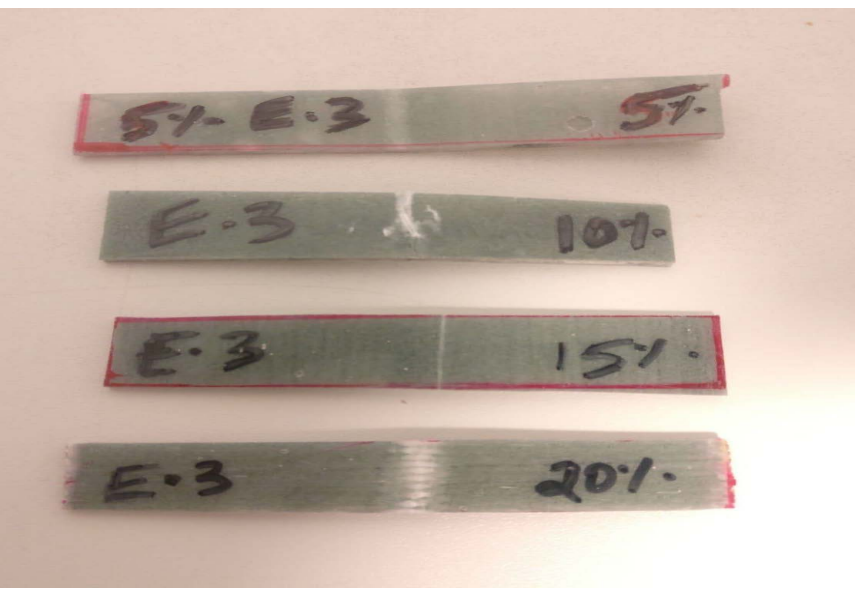

Figure 4. Flexural tested epoxy samples (SiC).

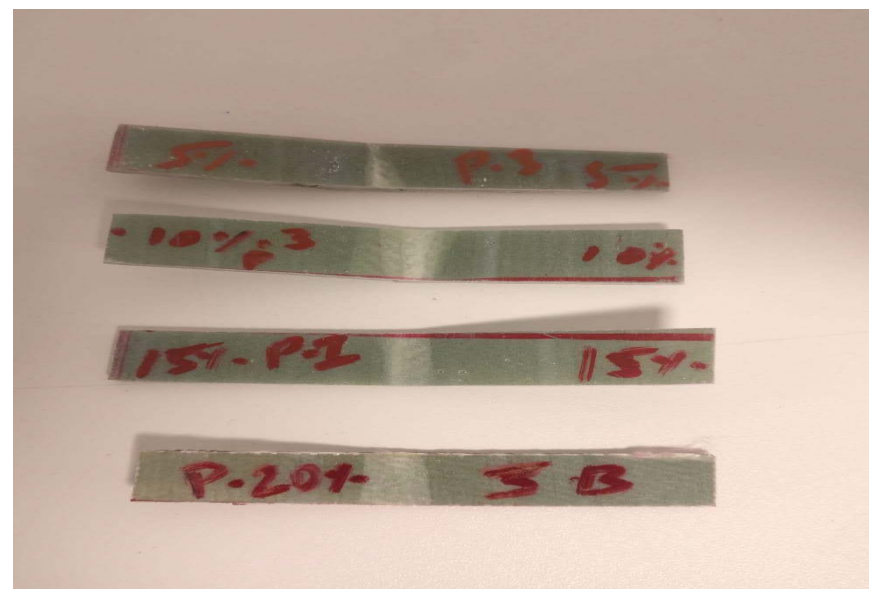

Figure 5. Flexural tested polyester samples ( $\mathrm{SiC})$. 
230 Celsius and relative humidity of $50 \%$.

\subsubsection{Charpy Impact Test}

The impact test specimens were prepared according to the ASTM-A370 standard. During testing, the specimen was loaded into a device and the pendulum was allowed to swing until it broke. Impact tests were used to measure the energy necessary to break the material, and this energy was used to determine the toughness and yield strength of the material. Impact testing was used to analyze the effect of strain rate on fracture and ductility of the material. Figure 6 and Figure 7 show the different specimens used for impact testing.

\subsubsection{Modelling}

Material properties play a significant role in determining parts produced by the Hand Lay-up method:

- Young's modulus;

- Tensile strength.

The following sections describe how they were modelled.

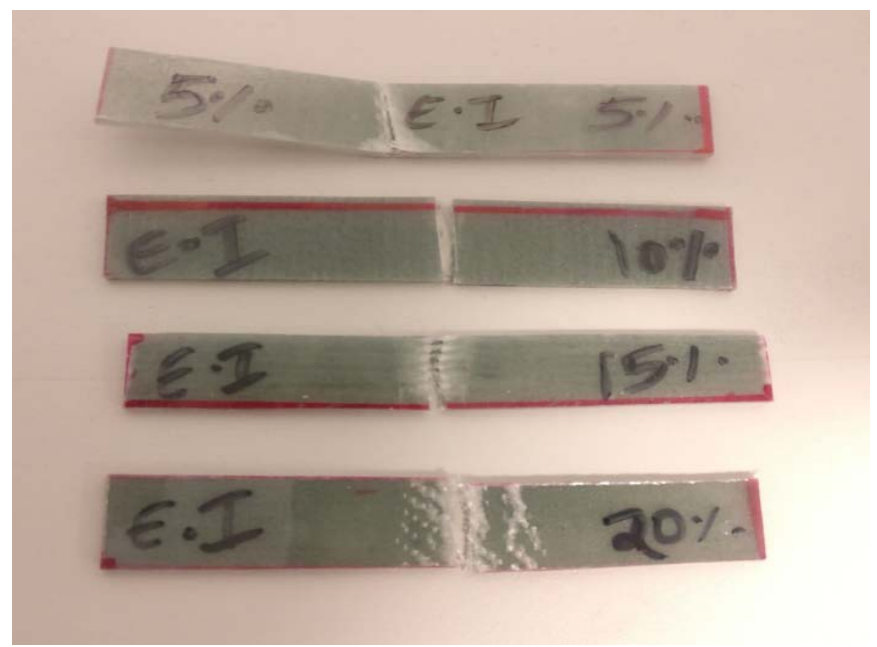

Figure 6. Impact tested epoxy samples with SiC.

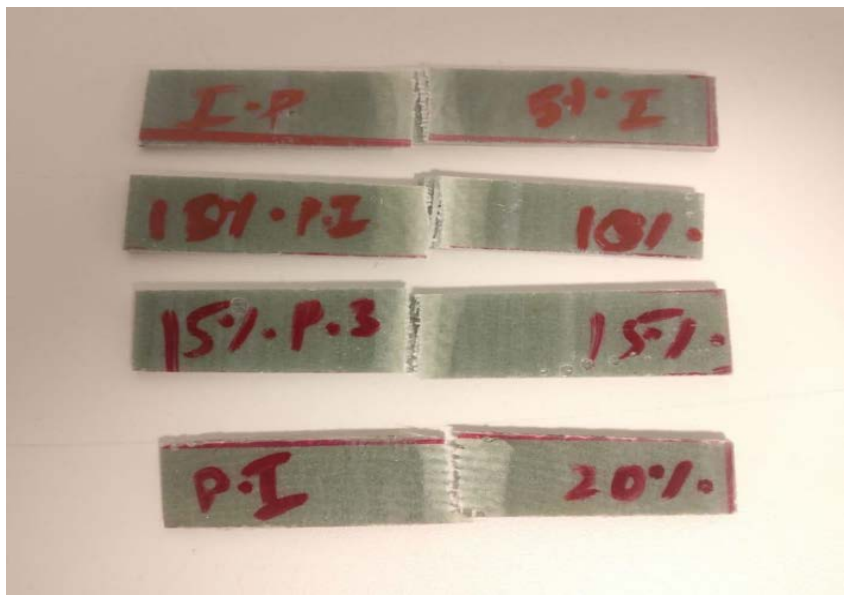

Figure 7. Impact tested polyester samples ( $\mathrm{SiC})$. 


\section{1) Young's modulus}

The Young's modulus of discontinuous fiber-reinforced material was calculated using the Cox model [12]:

$$
E_{/ / C}=E_{R_{/ /}} v_{R} \eta_{R} \eta_{L}+E_{P}\left(1-v_{R}\right)
$$

$E_{/ / C}$ : Young's modulus of discontinuous fiber-reinforced materials;

$E_{R_{/}}$: Young's modulus of reinforcement parallel to the longest axis;

$E_{P}$ : Young's modulus of the polymer;

$v_{R}$ : Volume fraction of reinforcement;

$\eta_{R}$ : Reinforcement orientation factor;

$\eta_{L}:$ Reinforcement length correction factor.

$$
\eta_{L}=1-\frac{\tanh \left(0.5 \beta L_{R}\right)}{0.5 \beta L_{R}}
$$

$L_{R}$ : Length of reinforcement.

$$
\eta_{L}=1-\frac{\tanh \left(0.5 \beta L_{R}\right)}{0.5 \beta L_{R}}
$$

$d_{R}:$ Diameter of reinforcement;

$G_{p}$ : Shear modulus of the polymer.

$$
\alpha=\frac{L_{R}}{d_{R}}
$$

With a being the aspect ratio, it can be written:

$$
\eta_{L}=1-\frac{\tanh \left(\alpha \sqrt{\frac{2 G_{p}}{E_{R_{I}} \ln \frac{D}{d_{R}}}}\right)}{\alpha \sqrt{\frac{2 G_{p}}{E_{R_{I}} \ln \frac{D}{d_{R}}}}}
$$

The shear modulus of the isotropic polymer was calculated by:

$$
G_{p}=\frac{E_{p}}{2\left(1+v_{p}\right)}
$$

The mean fiber separation (distance between their centroids), was expressed as:

$$
D=\frac{d_{R}}{\sqrt[4]{3}} \sqrt{\frac{\pi}{2 v_{R}}}
$$

\section{2) Tensile strength}

The tensile strength was modelled using the Verbeek model [13]:

$$
\sigma_{c}=\sigma_{p}\left(1-v_{R}\right)+K_{3} \tau_{p} M P F
$$

$\sigma_{c}:$ Tensile strength of composite;

$\sigma_{p}:$ Tensile strength of polymer; 
$\tau_{p}$ : Shear strength of polymer;

$K_{3}$ : Correction factor according to Verbeek (always: $K_{3}=0.75$ ).

$M P F$ : Stress reduction factor.

$$
M P F=v_{R} \frac{\alpha}{u}\left(\frac{1}{\tanh (u)}-\frac{1}{u}\right)
$$

$u$ : Packing fraction factor.

$$
u=\alpha \sqrt{\frac{G_{p} v_{R}}{E_{R}\left(1-v_{R}\right)}}
$$

\section{Results and Discussion}

\subsection{Tensile Properties}

In this study, $\mathrm{SiC}$ was used as reinforcement. The tensile properties were increased when compared to a previous study [14] where natural fibers were used as reinforcements. The graphs were plotted using the results of tensile tests on epoxy and polyester samples. As shown below in Figures 8-11.

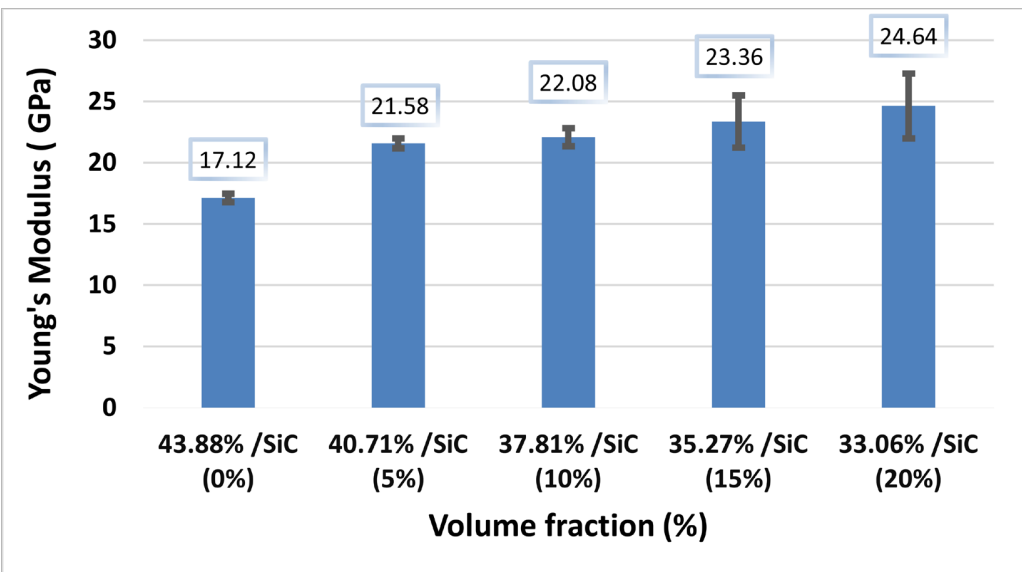

Figure 8. Young's modulus vs epoxy samples with SiC.

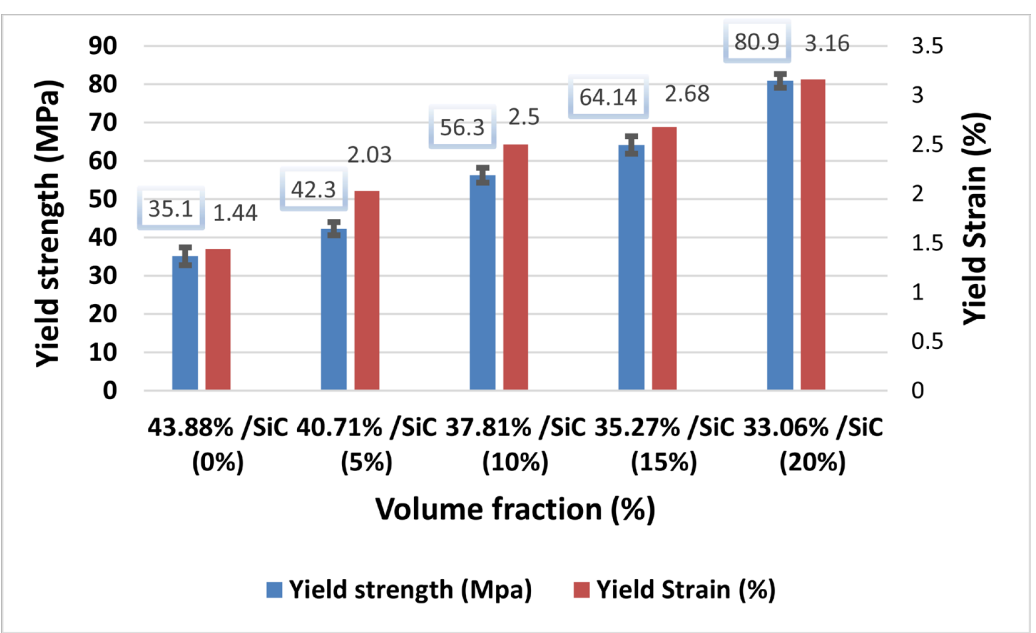

Figure 9. Yield strength vs yield strain (Epoxy samples with $\mathrm{SiC}$ ). 


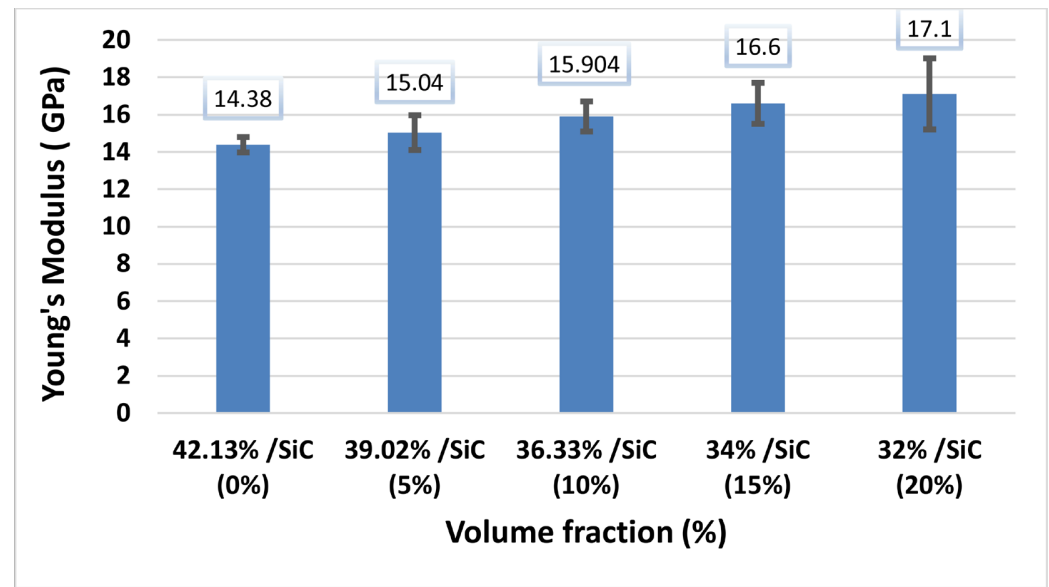

Figure 10. Young's modulus vs polyester samples with SiC.

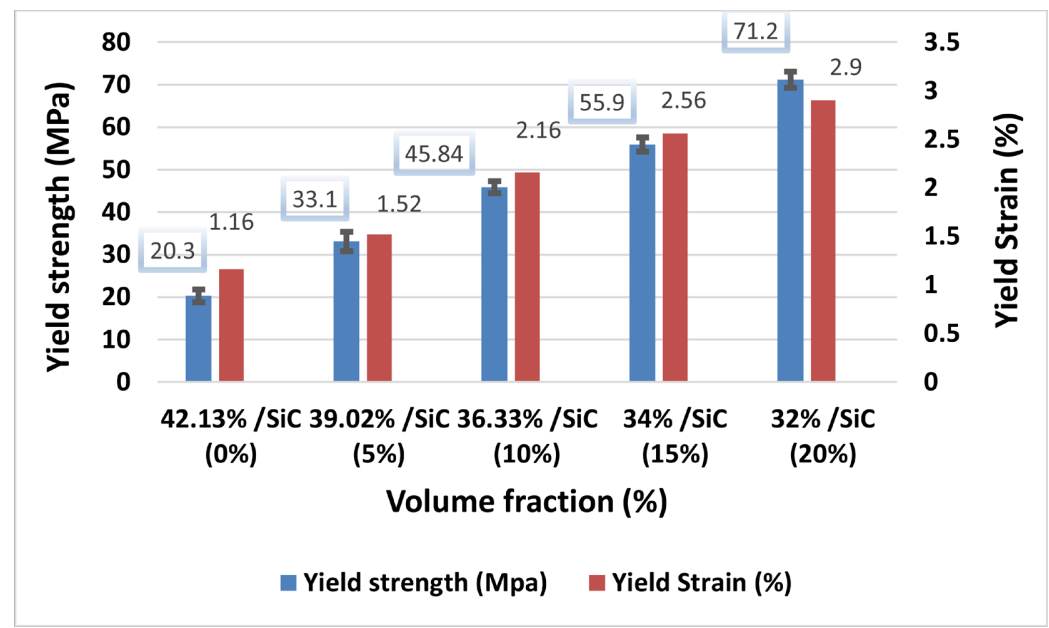

Figure 11. Yield strength vs yield strain (polyester samples with SIC).

\subsection{Flexural Test Result}

Tests were carried out on different percentages of $\mathrm{SiC}$ in glass fiber reinforced polymer composites to examine their flexural strength. Before reinforcement, the flexural strength of resin will be low due to brittleness. But after adding the reinforcements (glass fibers and $\mathrm{SiC}$ ) the flexural strength will be raised because the high modulus of elasticity of these fibers will help to carry a large number of loads and raise the strength. From, the result it is concluded that the epoxy samples possess high flexural modulus than the polyester samples. The graphs were plotted using the results of flexural tests on epoxy and polyester samples. As shown in Figure 12 and Figure 13. Furthermore, the flexural modulus was also higher in comparison to the study [14].

\subsection{Impact Test Result}

The results indicate that the epoxy samples have recorded the maximum value. The impact resistance will increase as the reinforcement percentage increases from $5 \%$ to $10 \%$. In addition to $\mathrm{SiC}$ reinforcement, resistance increased 
from $33.9 \mathrm{~kJ} / \mathrm{m}^{2}$ to $128.7 \mathrm{~kJ} / \mathrm{m}^{2}$. As a result, the impact resistance was increased since the reinforcements will carry the majority of the impact energy emitted by the composite material. The graphs were plotted using the results of Charpy impact tests on epoxy and polyester samples. As shown in Figure 14 and Figure 15.

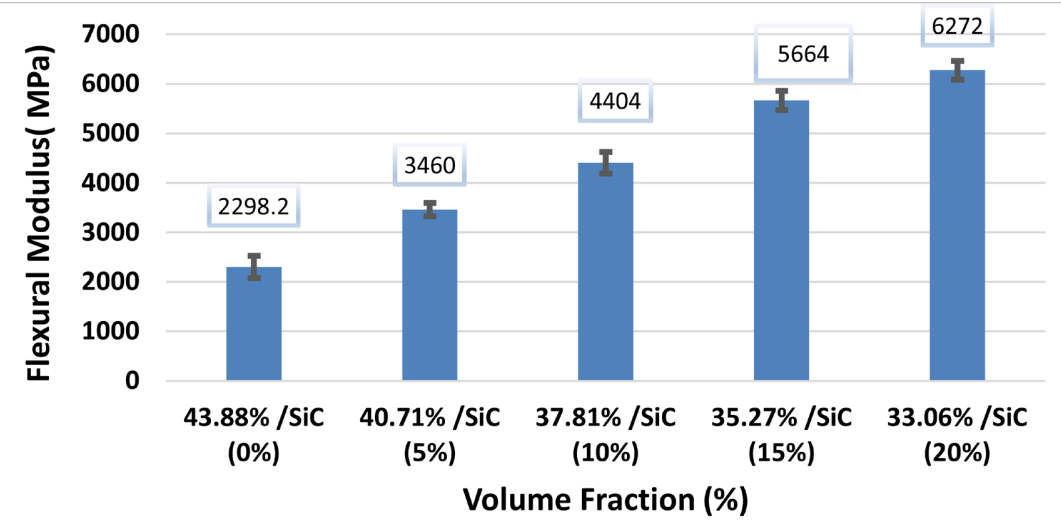

Figure 12. Flexural modulus vs epoxy samples with $\mathrm{SiC}$.

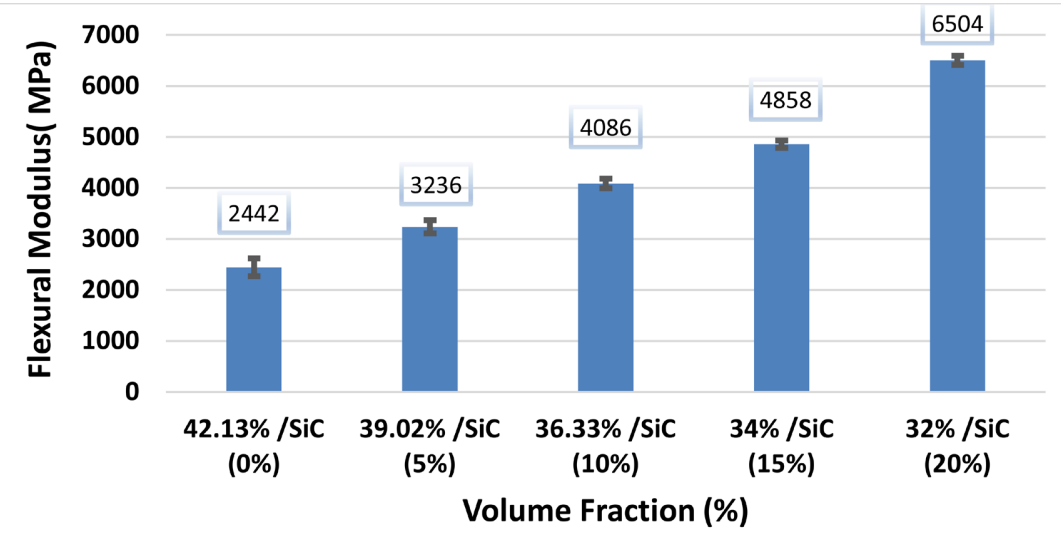

Figure 13. Flexural modulus vs polyester samples with SiC.

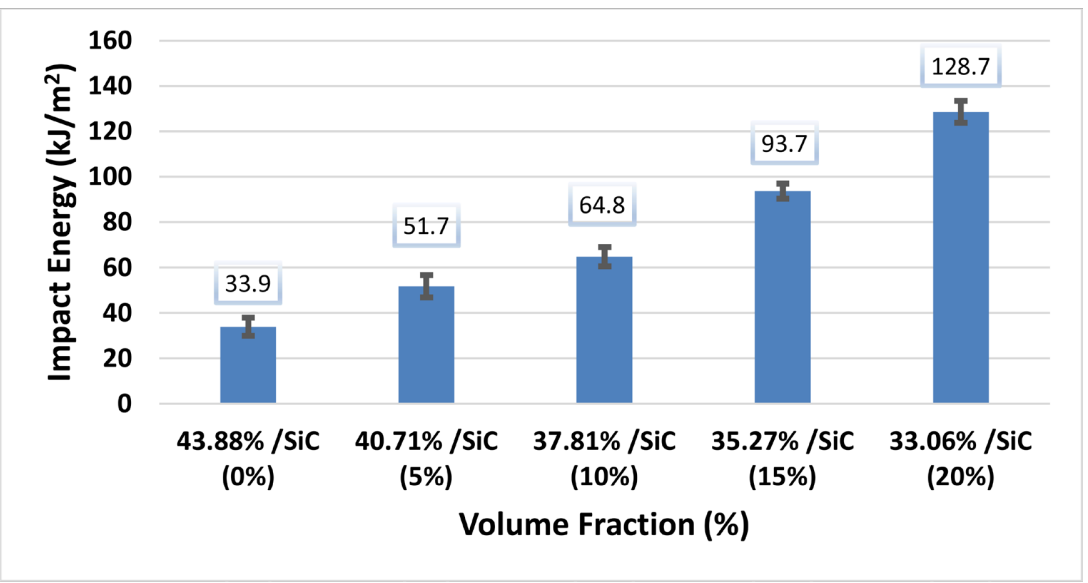

Figure 14. Impact energy vs epoxy samples with SiC. 


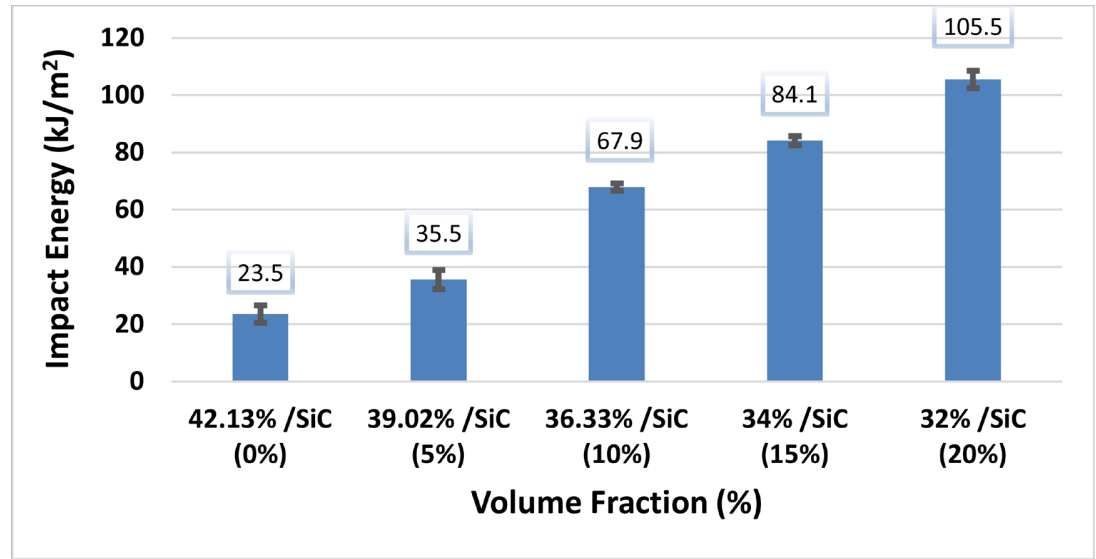

Figure 15. Impact energy vs polyester samples with $\mathrm{SiC}$.

\subsection{Modelled Result of Young's Modulus and Tensile Strength}

Modelled results of Young's modulus and tensile strength based on the mathematical models of Verbeek and Cox were shown as follows.

Table 2. Measured Young's modulus vs modelled moduli of epoxy and polyester samples.

\begin{tabular}{|c|c|c|c|c|c|}
\hline $\begin{array}{c}\text { Epoxy samples with } \\
\phi_{\mathrm{F}} \text { in }(\%) \text { and } \phi_{\mathrm{SiC}} \\
(\%)\end{array}$ & $\begin{array}{l}\text { Measured Young's } \\
\text { modulus } \mathrm{E}_{\mathrm{t}} \text { in } \\
(\mathrm{GPa})\end{array}$ & $\begin{array}{c}\text { Modelled moduli } \\
\text { of epoxy samples in } \\
(\mathrm{GPa})\end{array}$ & $\begin{array}{c}\text { Polyester samples } \\
\text { with } \phi_{\mathrm{F}} \text { in }(\%) \text { and } \\
\phi_{\mathrm{SiC}}(\%)\end{array}$ & $\begin{array}{c}\text { Measured Young's } \\
\text { modulus } \mathrm{E}_{\mathrm{t}} \text { in } \\
(\mathrm{GPa})\end{array}$ & $\begin{array}{l}\text { Modelled moduli of } \\
\text { Polyester samples in } \\
\text { (GPa) }\end{array}$ \\
\hline $43.88 \% / \mathrm{SiC}(0 \%)$ & 17.12 & 19.59 & $42.13 \% / \mathrm{SiC}(0 \%)$ & 17.06 & 14.38 \\
\hline $40.71 \% / \mathrm{SiC}(5 \%)$ & 21.58 & 22.33 & $39.02 \% / \mathrm{SiC}(5 \%)$ & 18.06 & 15.04 \\
\hline $37.81 \% / \mathrm{SiC}(10 \%)$ & 22.08 & 25.42 & $36.33 \% / \mathrm{SiC}(10 \%)$ & 19.33 & 15.9 \\
\hline $35.27 \% / \mathrm{SiC}(15 \%)$ & 23.36 & 26.23 & $34 \% / \mathrm{SiC}(15 \%)$ & 19.71 & 16.6 \\
\hline $33.06 \% / \mathrm{SiC}(20 \%)$ & 24.64 & 27.6 & $32 \% / \mathrm{SiC}(20 \%)$ & 20.22 & 17.1 \\
\hline
\end{tabular}

Table 3. Measured tensile strength vs modelled tensile strengths of epoxy and polyester samples with SiC.

\begin{tabular}{|c|c|c|c|c|c|}
\hline $\begin{array}{c}\text { Epoxy samples } \\
\text { with } \phi_{\mathrm{F}} \text { in (\%) and } \\
\phi_{\mathrm{SiC}}(\%)\end{array}$ & $\begin{array}{c}\text { Measured Tensile } \\
\text { strength } \sigma_{M} \text { in } \\
(\mathrm{GPa})\end{array}$ & $\begin{array}{l}\text { Modelled Tensile } \\
\text { strength of epoxy } \\
\text { samples in (GPa) }\end{array}$ & $\begin{array}{c}\text { Polyester samples } \\
\text { with } \phi_{\mathrm{F}} \text { in (\%) and } \\
\phi_{\mathrm{SiC}}(\%)\end{array}$ & $\begin{array}{c}\text { Measured Tensile } \\
\text { strength } \sigma_{M} \text { in } \\
(\mathrm{GPa})\end{array}$ & $\begin{array}{l}\text { Modelled Tensile } \\
\text { strength of Polyester } \\
\text { samples in (GPa) }\end{array}$ \\
\hline $43.88 \% / \mathrm{SiC}(0 \%)$ & 0.97 & 0.9 & $42.13 \% / \mathrm{SiC}(0 \%)$ & 0.62 & 0.9 \\
\hline $40.71 \% / \mathrm{SiC}(5 \%)$ & 1.03 & 1.0 & $39.02 \% / \mathrm{SiC}(5 \%)$ & 0.67 & 1.0 \\
\hline $37.81 \% / \mathrm{SiC}(10 \%)$ & 1.12 & 1.2 & $36.33 \% / \mathrm{SiC}(10 \%)$ & 0.82 & 1.1 \\
\hline $35.27 \% / \mathrm{SiC}(15 \%)$ & 1.19 & 1.5 & $34 \% / \mathrm{SiC}(15 \%)$ & 0.85 & 1.4 \\
\hline $33.06 \% / \mathrm{SiC}(20 \%)$ & 1.21 & 1.8 & $32 \% / \mathrm{SiC}(20 \%)$ & 0.98 & 1.7 \\
\hline
\end{tabular}




\section{Conclusions}

In this work, $\mathrm{SiC}$ reinforced composites using epoxy and polyester resin were produced with the hand lay-up technique by keeping glass fiber in many layers for better results. This method of fabrication was very simple and cost-effective. Their mechanical properties like yield strength, yield strain, Young's modulus, flexural modulus, and impact energy were investigated. The mechanical properties of the GFRP composites were also compared with the fiber volume fraction. The fiber volume fraction plays a major role in the mechanical properties of GFRP composites. The results were concluded as follows:

- As a result of adding silicon carbide filler to the composites, it provides very good stiffness. The shrinkage has been also reduced;

- From the samples with different compositions, the GFRP composite with epoxy resin has a very high Young's modulus of $24.64 \mathrm{GPa}$;

- The composites with GFRP and epoxy resin have higher impact energies, with a value of $128 \mathrm{~kJ} / \mathrm{m}^{2}$;

- The flexural modulus was more in GFRP composite with a polyester resin of $6504 \mathrm{MPa}$;

- With the Cox and Verbeek models, the modelling process was carried out and, when the modelled and measured values were compared, the results were optimal for epoxy and polyester resin composites. Composites made of polyester resin have a lower modelled Young's modulus and tensile strength than epoxy resin composites, as shown in Table 2 and Table 3.

\section{Acknowledgments}

The authors acknowledge the financial support provided by the Institute for Plastics Engineering West Pfalz (IKW). It is a scientific institution of the Department of Applied Logistics and Polymer Sciences and a research and testing institute at the university located in Pirmasens in the field of reinforced and unreinforced plastics. Besides implementing public and industrially supported projects, it also helps in the development of plastic components beginning with the selection of their materials and construction. Their core competencies are in ultrasonic testing of fiber composite components according to EN4179, measurement of thermal conductivities, 3D web, statistically-based compounding, tribology with friction partner ice and rotational molding.

\section{Conflicts of Interest}

The authors declare no conflicts of interest regarding the publication of this paper.

\section{References}

[1] Miracle, D.B. and Donaldson, S.L. (1990) Introduction to Composites. In: Henry, S.D., Moosbrugger, C., Muldoon, K. and Scott, W.W.J., Eds., ASM Handbook of Composite Materials, vol. 21, ASM International, Materials Park, Ohio, 90-115. 
[2] Ozben, T., Kilickap, E. and Çakir, O. (2008) Investigation of Mechanical and Machinability Properties of SiC Particle Reinforced Al-MMC. Journal of Materials Processing Technology, 198, 220-225. https://doi.org/10.1016/j.jmatprotec.2007.06.082

[3] Romanzini, D., Junior, H.L.O., Amico, S.C. and Zattera, A.J. (2012) Preparation and Characterization of Ramie-Glass Fiber Reinforced Polymer Matrix Hybrid Composites. Materials Research, 15, 415-420. https://doi.org/10.1590/S1516-14392012005000050

[4] Moorthy, S.S. and Manonmani, K. (2013) Fabrication and Characterization of TiO2 Particulate Filled Glass Fiber Reinforced Polymer Composite. Materials Physics and Mechanics, 18, 28-34.

[5] EL-Wazerya, M.S., EL-Elamyb, M.I., Razzaquec, S.H. and Abdur, M. (2017) Mechanical Properties of Glass Fiber Reinforced Polyester Composites. International Journal of Applied Science and Engineering, 14, 121-131.

[6] Rajesh, S., Ramnath, B.V., Elanchezhian, C., Aravind, N., Rahul, V.V. and Sathish, S. (2014) Analysis of Mechanical Behavior of Glass Fiber $/ \mathrm{Al}_{2} \mathrm{O}_{3}-\mathrm{SiC}$ Reinforced Polymer Composite. Procedia Engineering, 97, 598-606.

https://doi.org/10.1016/j.proeng.2014.12.288

[7] Yamunadevi, V., Palaniradja, K., Thiagarajan, A., Ganeshan, P. and Raja, K. (2019) Characterization and Dynamic Mechanical Analysis of Woven Roving Glass Fiber/Cerium-Zirconium Oxide Epoxy Nanocomposite Materials. Materials Research Express, 6, Article No. 095057. https://doi.org/10.1088/2053-1591/ab2f64

[8] Abdullah, E.T. (2013) A Study of Bending Properties of Unsaturated Polyester/Glass Fiber Reinforced Composites. Journal of Al-Nahrain University, 16, 129-132. https://doi.org/10.22401/JNUS.16.3.18

[9] Davallo, M. and Pasdar, H. (2009) Comparison of Mechanical Properties of Glass-Polyester Composites Formed by Resin Transfer Molding and Hand Lay-Up Technique. International Journal of Chem Tech Research, 1, 470-475.

[10] Bedir, F. and Ogel, B. (2004) Investigation of Hardness, Microstructure and Wear Properties of Silicon Carbide Particles Reinforced Al Composites. Proceeding of the 11 th International Conference on Machine Design and Production, Turkey, 15 October 2004.

[11] Swapnil, A.S., SatheSandip, B., ChaudhariBapu, P. and Vishal, S.J. (2017) Experimental Investigation of Mechanical Properties of Glass Fibre/Epoxy Composites with Variable Volume Fraction. Materials Today. Proceedings, 4, 9487-9490.

https://doi.org/10.1016/j.matpr.2017.06.209

[12] Cox, H.L. (1952) The Elasticity and Strength of Paper and Other Fibrous Materials. British Journal of Applied Physics, 3, 72-79.

https://doi.org/10.1088/0508-3443/3/3/302

[13] Verbeek, C.J.R. (2003) The Influence of Interfacial Adhesion, Particle Size and Size Distribution on the Predicted Mechanical Properties of Particulate Thermoplastic Composites. Material Letters, 57, 1919-1924.

https://doi.org/10.1016/S0167-577X(02)01105-9

[14] Rajesh, S., Vijaya, R., Elanchezhian, C., Shankar, A., Pithchai, S., Vickneshwaran, S. and Rajan, R. (2015) Investigation on Mechanical Behaviour of Twisted Natural Fiber Hybrid Composite Fabricated by Vacuum-Assisted Compression Molding Technique. Fibers and Polymers, 17, 80-87. 